\title{
Exposure to disinfectants (soap or hydrogen peroxide) increases tolerance to permethrin in Anopheles gambiae populations from the city of Yaoundé, Cameroon
}

\author{
Christophe Antonio-Nkondjio ${ }^{1,4^{*}}$, Marlene Youmsi-Goupeyou ${ }^{1,2}$, Edmond Kopya ${ }^{1,2}$, Billy Tene-Fossog ${ }^{1,2}$, \\ Flobert Njiokou ${ }^{2}$, Carlo Costantini ${ }^{1,3}$ and Parfait Awono-Ambene ${ }^{1}$
}

\begin{abstract}
Background: The rapid expansion of insecticide resistance is limiting the efficiency of malaria vector control interventions. However, current knowledge of factors inducing pyrethroid resistance remains incomplete. In the present study, the role of selection at the larval stage by disinfectants, such as soap and hydrogen peroxide $\left(\mathrm{H}_{2} \mathrm{O}_{2}\right)$, on adult mosquito resistance to permethrin was investigated.

Methods: Field Anopheles gambiae sensu lato larvae, were exposed to variable concentrations of soap and $\mathrm{H}_{2} \mathrm{O}_{2}$. Larvae surviving to acute toxicity assays after 24 hours were reared to the adult stage and exposed to permethrin. The susceptibility level of adults was compared to the untreated control group. The effect of soap or hydrogen peroxide selection on the length of larval development and emergence rate was assessed.

Result: Larval bioassays analysis showed a more acute effect of hydrogen peroxide on mosquito larvae compared to soap. The regression lines describing the dose mortality profile showed higher mean and variance to hydrogen peroxide than to soap. The duration of larval development ( $<5$ days) and adults emergence rates ( 1 to $77 \%)$ were shorter and lower compare to control. Anopheles gambiae s.l. larvae surviving to selection with either soap or hydrogen peroxide or both, produced adults who were up to eight-times more resistant to permethrin than mosquitoes from the untreated control group.
\end{abstract}

Conclusion: The present study shows that selective pressure exerted by non-insecticidal compounds such as soap and hydrogen peroxide affect An. gambiae s.l. tolerance to pyrethroids. This requires further studies with regard to the adaptation of An. gambiae s.l. to polluted habitats across sub-Saharan Africa cities.

Keywords: Anopheles gambiae, Soap, Hydrogen peroxide, Permethrin tolerance, Selection

\section{Background}

Insecticide-based interventions (IRS and LLINs) represent the main strategy for malaria prevention across subSaharan Africa [1]. However, the effectiveness of these control measures is threatened by the rapid expansion of insecticide resistance [2]. Identifying the sources of

\footnotetext{
* Correspondence: antonio_nk@yahoo.fr

'Laboratoire de Recherche sur le Paludisme, Organisation de Coordination pour la lutte Contre les Endémies en Afrique Centrale (OCEAC), P.O. Box 288, Yaoundé, Cameroon

${ }^{4}$ Vector group, Liverpool School of Tropical Medicine, Pembroke Place, Liverpool L3 5QA, UK

Full list of author information is available at the end of the article
}

pyrethroid resistance is becoming crucial and adheres to WHO Global Plan for Insecticide Resistance Management [3]. The majority of insecticides currently in used in public health are also used as pesticides in agriculture. The fact that large quantities of these compounds are used as agrochemicals is considered to have favoured the emergence and spread of pyrethroid resistance [4-6]. In Cameroon, consistent with a strong selective pressure exerted by agricultural use of insecticides, high prevalence of insecticide resistance was reported in areas with large agro-industrial estates, extensive cotton cultivation or market gardening [4,5,7-9]. With the rapid expansion 
of unplanned urbanization in the cities of Douala and Yaoundé, DDT and pyrethroid resistance was also reported to be highly prevalent in Anopheles gambiae populations emerging from both agricultural cultivated sites and polluted sites $[10,11]$. Bionomic studies assessing the distribution of Anopheles coluzzii and An. gambiae formally known as molecular forms $\mathrm{M}$ and $\mathrm{S}$ respectively in the city of Yaoundé, revealed high tolerance of An. coluzzii present in the city centre to ammonia compared to An. gambiae highly prevalent in the city suburbs $[12,13]$. Whether physiological changes, which have contributed to shape the distribution of $A n$. gambiae and An. coluzzii in the city of Yaoundé, is affecting mosquito tolerance to insecticides is still to be ascertained. However, the fast evolution of insecticide resistance in the city of Yaoundé suggests the possible implication of several factors responsible for generating selective pressure and requires further attention. In their natural habitats, mosquitoes are usually exposed to a large set of conditions which affect their fitness, development, distribution and level of susceptibility to insecticides [14]. Thermal adaptation was reported to increase Anopheles stephensi susceptibility to Plasmodium infection and tolerance to insecticides, such as carbamates and malathion $[15,16]$. Pre-exposure to several compounds including heavy metals, plant allelochemicals or petroleum products are also considered to induce in insects crossresistance to insecticides [17-21]. Meanwhile despite the huge amount of disinfectants such as soap or hydrogen peroxide $\left(\mathrm{H}_{2} \mathrm{O}_{2}\right)$ regularly eliminated in the environment their impact on mosquito populations bionomic has so far been poorly explored across sub-Saharan Africa. Hydrogen peroxide and different formulations of soap including commercial or antibacterial soaps were shown to have a larvicide effect against several pest insects or to be lethal to several organisms [22-24]. Soap is manufacture by mixing fatty acids to a salt $(\mathrm{NaOH}$ or $\mathrm{KOH})$ but more formulations include active ingredients (antibacterial), which most of the time increase the larvicide effect [23]. This making that, new formulations of soap might even be more toxic against arthropods than previous [23,25]. Because of lack of appropriate drainage systems in sub-Saharan cities, the large majority of pollutants released by anthropogenic activities are eliminated in the environment and these compounds accumulate in rivers or stagnant water bodies. Despite their toxicity, their impact on the dynamic of the aquatic fauna and the natural ecosystem is poorly understood. In the current study, the role of selection at the larval stage by soap and hydrogen peroxide $\left(\mathrm{H}_{2} \mathrm{O}_{2}\right)$ on adult mosquito resistance to permethrin was assessed.

\section{Methods}

Study sites

The study took place in Yaoundé $\left(3^{\circ} 51^{\prime} \mathrm{N} 11^{\circ} 30^{\prime} \mathrm{E}\right)$, the capital city of Cameroon. The city is situated within the
Congo-Guinean phytogeographic zone characterized by a typical equatorial climate with two rainy seasons extending from March to June and from September to November. The annual average rainfall in Yaoundé is $1,700 \mathrm{~mm}$. The city is situated $800 \mathrm{~m}$ above sea level and is surrounded by many hills. Larval collections in Yaoundé were carried out in five districts situated in the city centre: Mokolo, Messa, Olezoa, Ahala and Combattant. The study was conducted under the ethical clearance $\mathrm{N}^{\circ}$ 216/CNE/SE/09 delivered by the Cameroon National Ethics Committee Ref No IORG0006538-IRB00007847FWA00016054.

\section{Mosquito identification}

Anopheline larvae were identified morphologically using the Gillies and Coetzee keys [26]. Mosquitoes belonging to the $A n$. gambiae complex were subjected to PCR assays designed for species and molecular forms identifications [27]. Genomic DNA used for molecular analysis was extracted from larvae according to Cornel [28] protocols.

\section{Bioassay experimentations \\ Preparation of test solutions for larvae bioassays}

Stock solutions and serial dilutions were prepared starting from commercial solutions of soap (lemon dish liquid, Colgate Palmolive Cameroon) and hydrogen peroxide $\left(\mathrm{H}_{2} \mathrm{O}_{2}\right)$ (Laboratoires Gilbert, France) following the protocol described in WHO guidelines [29]. A stock solution at $5 \%$ was prepared by mixing the corresponding volume of soap or $\mathrm{H}_{2} \mathrm{O}_{2}$ to distilled water. Test concentrations were prepared by serial dilutions in distilled water to obtain a final test volume of a $100 \mathrm{ml}$.

\section{Experimental procedure of bioassays with larvae}

Preliminary bioassays were conducted to assess the toxicity of soap or $\mathrm{H}_{2} \mathrm{O}_{2}$ on a susceptible strain (The Yaoundé laboratory colony consisting exclusively of $A n$. coluzzii and known to be susceptible to pyrethroids). Following these bioassays a range of concentrations was then determined for assessing field larvae susceptibility.

Field collected An. gambiae sensu lato (s.l.) larvae, were divided in two separate groups the treated and untreated groups. The treated group consisting of third instars were exposed in $100 \mathrm{ml}$ freshly prepared soap or $\mathrm{H}_{2} \mathrm{O}_{2}$ solution at the required concentration. At least seven different concentrations were tested and 10 to 20 replicates conducted. Control cups had $100 \mathrm{ml}$ of distilled water. Batches of 25 to 30 larvae were distributed per cup. Larvae of each breeding site were exposed to all test concentrations. After an initial observation period of 2 hours in distilled water, larvae were transferred into test cups with the required xenobiotic concentration. Larval mortality was recorded after 24 hours exposure (Figure 1). 


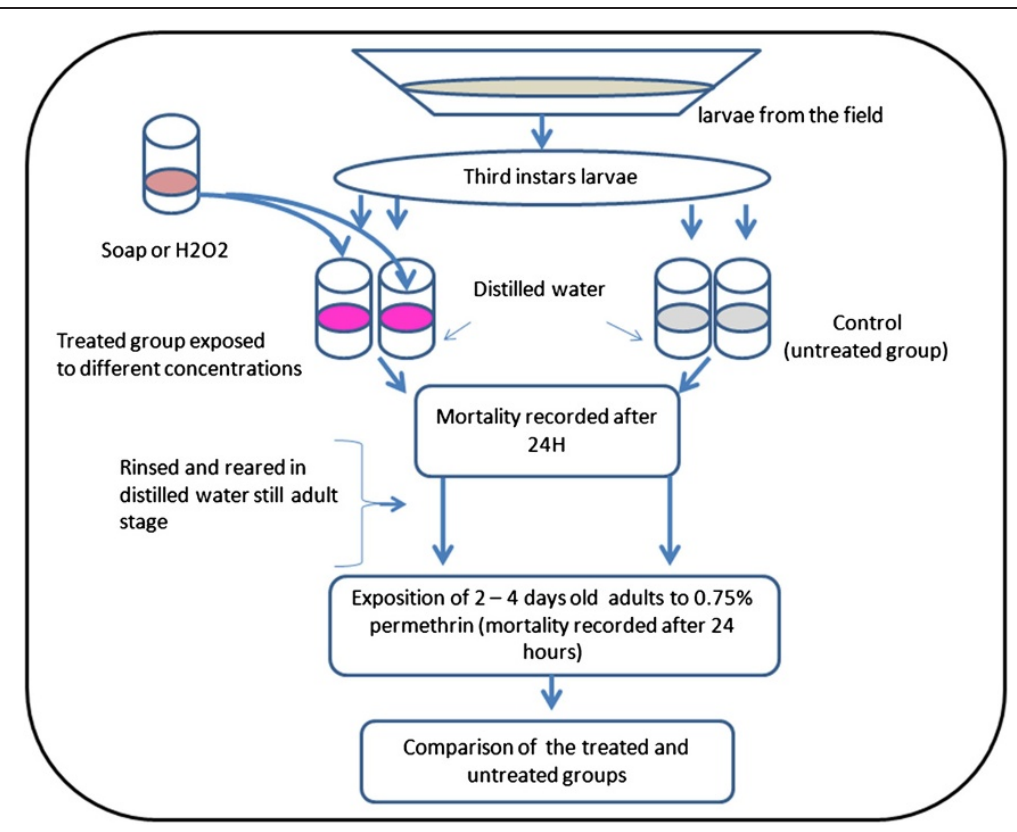

Figure 1 A graph describing the experimental design of the study.

Larvae were considered dead when they were incapable of any active movement when touched. The mortality rate was corrected by the formula of Abbott [30] if it was between 5\% and 20\%. The lethal concentration killing 50\% and $95 \%$ of larvae (LC50 and LC90) was calculated. Mosquito of the untreated control group were placed in distilled water during the experiment.

\section{Adults susceptibility tests}

Larvae surviving exposure to soap or $\mathrm{H}_{2} \mathrm{O}_{2}$ and larvae from the untreated control group, were reared in distilled water until the adult stage before being exposed to $0.75 \%$ permethrin. Insecticide susceptibility tests were performed with two- to four-day-old unfed An. gambiae s.l. females. Batches of 20 to 25 mosquitoes per tube were exposed to permethrin $(0.75 \%)$ impregnated papers (supplied by Dr Wondji of, Liverpool School of Tropical Medicine, UK) for one hour. The number of mosquitoes knocked down by the insecticide was recorded every 5 minutes during exposure. After exposure, mosquitoes were fed with a $10 \%$ glucose solution and the number of dead mosquitoes was recorded 24 hours post-exposure. Tests using untreated papers were systematically run as controls. The mortality rates were corrected using the Abbot formula [30] whenever the mortality rate of the controls was between 5 and 20\%. World Health Organization criteria [31] were used to evaluate the resistance and susceptibility status of the mosquito population tested. Three classes of insecticide susceptibility were defined: insecticide resistant $(<80 \%)$, insecticide tolerant (80 to $97 \%$ ), and insecticide susceptible ( $>97 \%$ ).
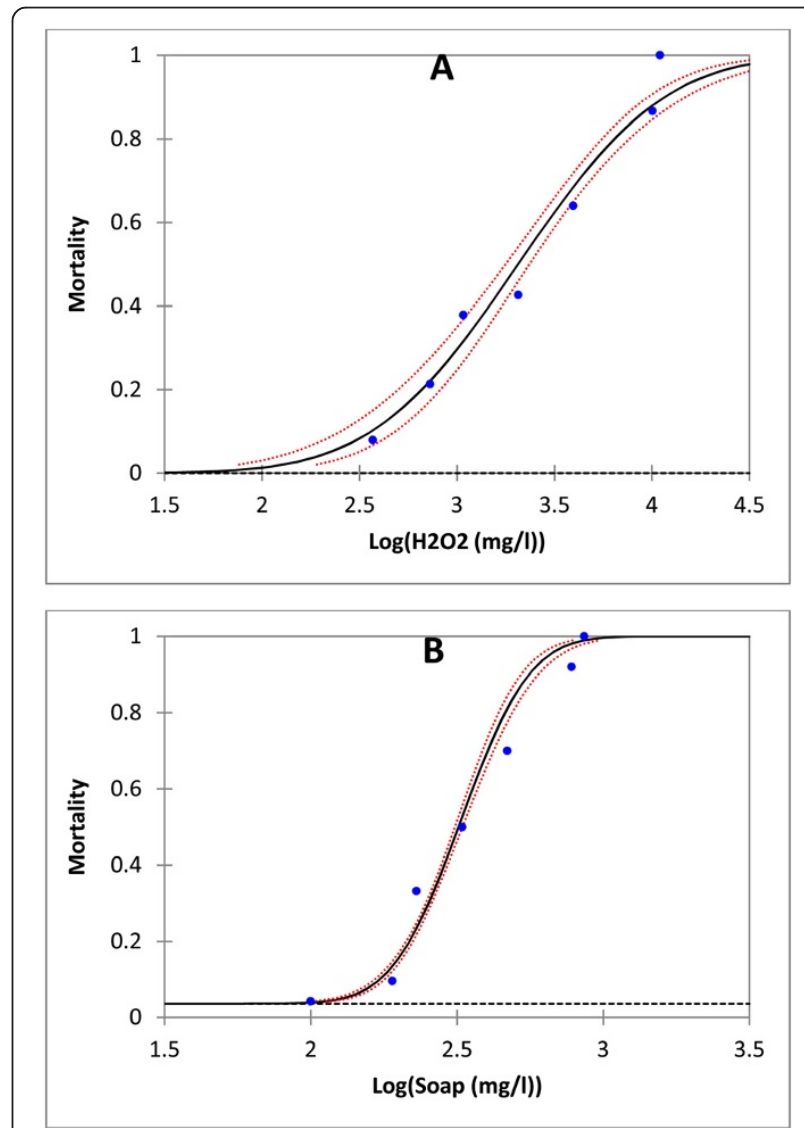

Figure 2 Dose mortality curve for Anopheles gambiae s.l. larvae form Yaoundé exposed to hydrogen peroxide $\left(\mathrm{H}_{2} \mathrm{O}_{2}\right)(\mathrm{A})$ and soap (B) for $\mathbf{2 4}$ hours. Logistic regression line was fitted to dose response data using a XLSTAT 2013. In red dots the $\pm 95 \%$ confidence limits. 
Table 1 Estimates of the lethal concentration doses (LC50 and LC95) of hydrogen peroxide $\left(\mathrm{H}_{2} \mathrm{O}_{2}\right)$ and Soap calculated from generalized linear models assessing the effect of $\mathrm{H}_{2} \mathrm{O}_{2}$ and soap concentration (expressed in mg/l) on Anopheles gambiae s.l. larval mortality

\begin{tabular}{ccccccr}
\hline \multicolumn{7}{c}{ Lethal Concentration (LC) } \\
\hline Species & $\mathrm{N}$ & $\mathrm{LC50}(95 \% \mathrm{Cl})$ & $\mathrm{LC95}(95 \% \mathrm{Cl})$ & $\mathrm{N}$ & $\mathrm{LC50}(95 \% \mathrm{Cl})$ & $\mathrm{L}$ \\
An. gambiae s.l. & 7,204 & $320.1(311.2-330.2)$ & $651.3(605-709.9)$ & 4,962 & $2060.8(1776-2353.9)$ & $19059.9(14903.7-26069)$ \\
\hline
\end{tabular}

$\mathrm{N}$, Number of larvae tested; $95 \% \mathrm{Cl}, 95 \%$ confidence limits.

\section{Statistical analysis}

Using a log-probit regression analysis, the toxicity effect of $\mathrm{H}_{2} \mathrm{O}_{2}$ or soap on mosquito larvae mortality was computed and lethal concentrations LC50 and LC95 were determined using the software XLSTAT. The estimation uses the iterative method of maximum likelihood to fit a linear regression between the log of insecticide concentration and the probit of mortality. Comparison of the prevalence between groups was performed using chi square test. Estimates of odd ratio values between adult mortality rates and lethal concentrations used for larval selection were computed using the software MedCalc V11.5.0.0.

\section{Results}

Assessment of lethal concentrations of Soap and $\mathrm{H}_{2} \mathrm{O}_{2}$ on Anopheles gambiae s.l. larvae

A total of 7,204 field An. gambiae larvae were exposed to various concentrations of soap and 4962 to various concentrations of $\mathrm{H}_{2} \mathrm{O}_{2}$. A probit regression model was used to assess the effect of soap and hydrogen peroxide $\left(\mathrm{H}_{2} \mathrm{O}_{2}\right)$ on third instars larvae mortality. A positive and significant correlation between larval mortality and log (dose) of soap or $\mathrm{H}_{2} \mathrm{O}_{2}$ was recorded ( $\left.\mathrm{p}<0.001\right)$. The regression lines describing the dose mortality response of mosquitoes to soap or peroxide hydrogen, showed some differences in the distribution of individual tolerance thresholds to these two pollutants. Higher mean and variance was recorded with $\mathrm{H}_{2} \mathrm{O}_{2}$ than with soap (Figure 2). The natural mortality calculated by the model was respectively $3.6 \%$ for soap and $0 \%$ for $\mathrm{H}_{2} \mathrm{O}_{2}$ and was not significantly different from observed mortality in the untreated control groups (3.1\% for soap and $1.8 \%$ for $\mathrm{H}_{2} \mathrm{O}_{2}$ ) $(\mathrm{P}>0.4)$ and confirm that, no other factor was inducing larval mortality. The LC50 and LC95 lethal concentrations estimated are presented in Table 1.

\section{Molecular identification of mosquito processed}

In total, 197 specimens were analysed to determine species and molecular forms of the An. gambiae complex, three specimens were $A n$. gambiae (S molecular form), the remaining 194 (98\%) specimens were An. coluzzii (M molecular form).

Chronic sub-lethal effect of selection by soap and $\mathrm{H}_{2} \mathrm{O}_{2}$ on An. gambiae development at the larval stage

Third instar An. gambiae larvae recorded as survivors after 24 hours exposure were rinsed and reared in distilled water until adult stage to assess the effect of selection by soap and $\mathrm{H}_{2} \mathrm{O}_{2}$ on larval development in laboratory conditions. Larvae pre-exposed to soap or $\mathrm{H}_{2} \mathrm{O}_{2}$, showed high emergence rate $(41 \%, 77 \%)$ when exposed to lower concentrations while higher mortality was recorded with higher concentrations (Table 2). The average duration of larval development was reduced compare to control and varied from 4.43 to 4.96 days for larvae pre-exposed to soap and 4.33 to 4.89 for larvae pre-exposed to $\mathrm{H}_{2} \mathrm{O}_{2}$ (Table 2). A significant evolution of daily mortality compare to control $(\mathrm{P}<0.001)$ was recorded after mosquito pre-exposure to $\mathrm{H}_{2} \mathrm{O}_{2}$ or soap.

Table 2 Effect of pre-exposure to soap or hydrogen peroxide $\left(\mathrm{H}_{2} \mathrm{O}_{2}\right)$ on An. gambiae larvae emergence rate and length of larval development

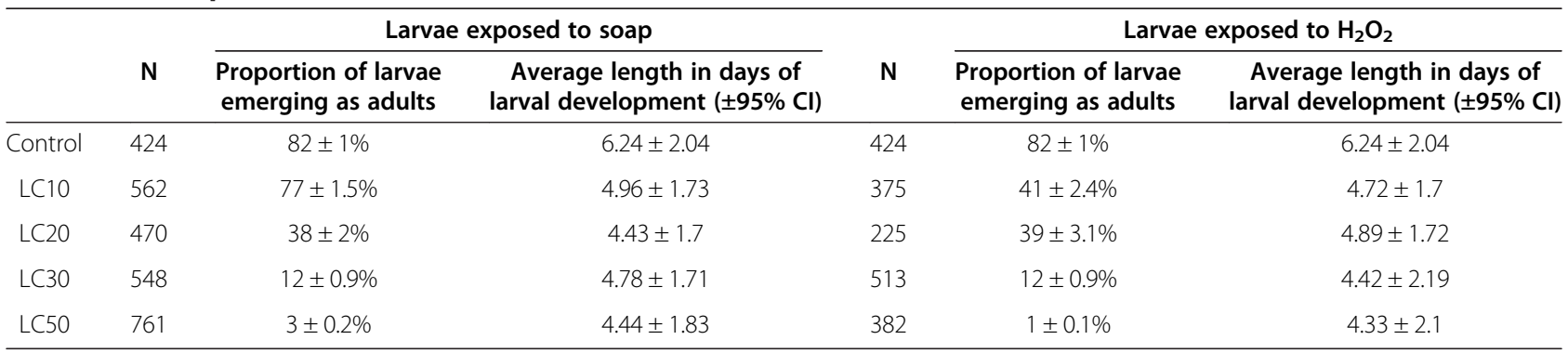

$\mathrm{N}$, Number of larvae; $95 \% \mathrm{Cl}, 95 \%$ confidence limits. 


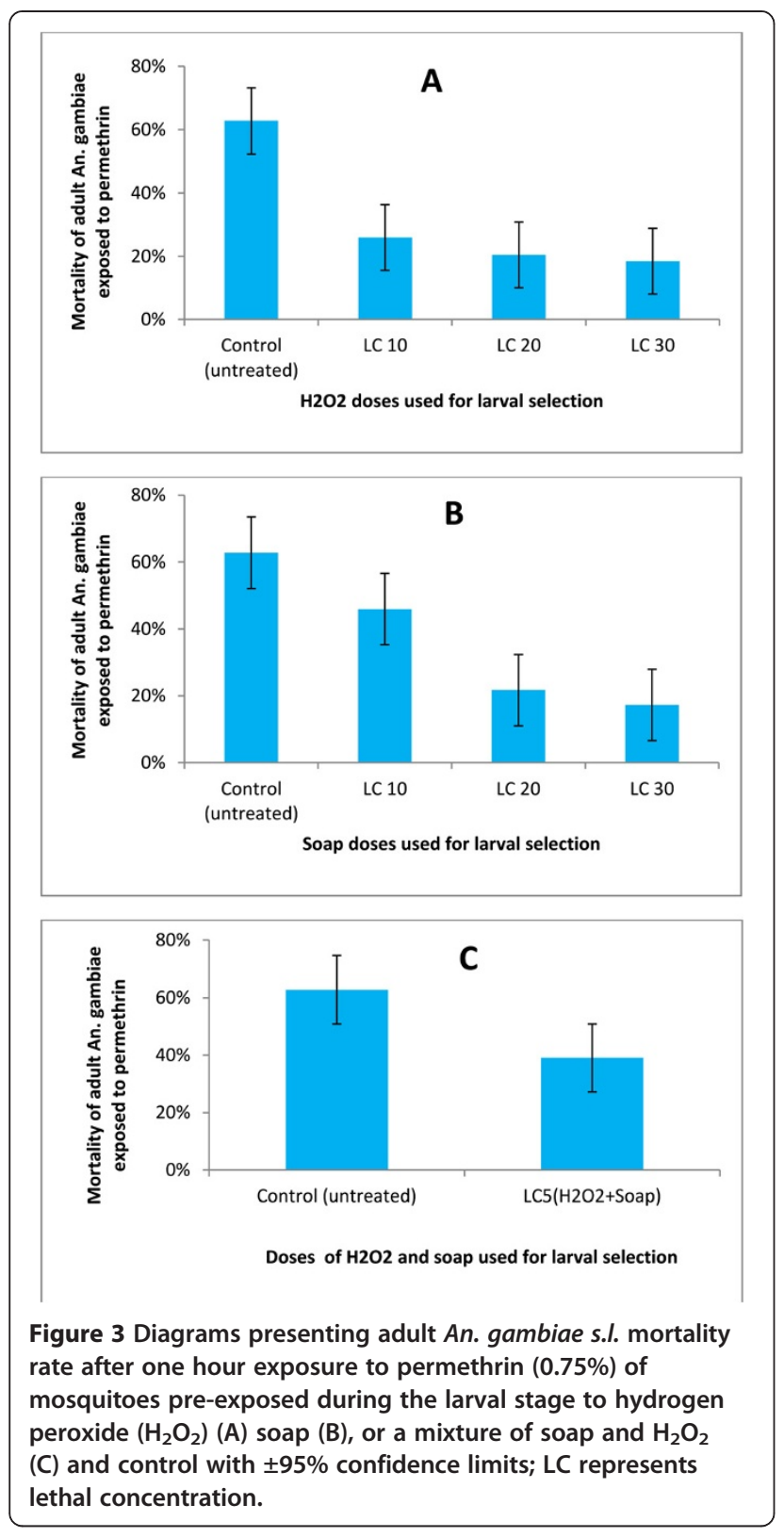

Effect of larval tolerance to soap or $\mathrm{H}_{2} \mathrm{O}_{2}$ on adult Anopheles gambiae resistance to permethrin

Larvae surviving at different concentrations of soap or $\mathrm{H}_{2} \mathrm{O}_{2}$ were reared to the adult stage and susceptibility to permethrin $(0.75 \%)$ after one hour exposure using WHO standard bioassays was conducted [31]. Increased tolerance of mosquitoes pre-exposed to soap or $\mathrm{H}_{2} \mathrm{O}_{2}$ was recorded compare to the untreated control. A similar trend was recorded when mosquitoes were exposed to a mixture of soap and $\mathrm{H}_{2} \mathrm{O}_{2}$ at low concentrations (Figure 3). The level of tolerance at the adult stage appeared significantly dependant of the concentration of soap or $\mathrm{H}_{2} \mathrm{O}_{2}$ used for larval selection. Further analysis assessing the strength of cross resistance to either soap or $\mathrm{H}_{2} \mathrm{O}_{2}$ and permethrin showed that larvae expressing tolerance to higher concentration of soap or $\mathrm{H}_{2} \mathrm{O}_{2}$ produced adults who were seven to eight times more resistant to permethrin than the untreated control (Table 3).

\section{Discussion}

Despite the rapid expansion of insecticide resistance in Cameroon cities $[4,5,32]$, cross-resistance between noninsecticide chemicals and pyrethroids in mosquito populations has received until date little attention. In the present study, the relationship between An. gambiae s.l. larval survival to disinfectants respectively soap and hydrogen peroxide $\left(\mathrm{H}_{2} \mathrm{O}_{2}\right)$ and resistance of adult mosquitoes to permethrin was investigated. The study reveals that mosquitoes exposed during the larval stage to soap or hydrogen peroxide were significantly more tolerant at the adult stage to permethrin than control (untreated group). The findings are consistent with previous studies indicating that thermotolerance or exposure to heavy metals or natural xenobiotics, is capable of increasing mosquito resistance to insecticides and/or detoxification genes expression $[16,19,20,33]$. Large variance in the tolerance level of field larvae to soap and $\mathrm{H}_{2} \mathrm{O}_{2}$ was recorded and could likely be associated to prior selection by pollutants present in natural breeding sites. Hydrogen peroxide and soap, are two compounds which presence in the nature is largely associated to anthropogenic activities. Hydrogen peroxide is known for its toxic effect for different living being [24]. Soap on the other hand is a detergent largely used in domestic activities. Commercial soap was demonstrated to be toxic to crickets, American cockroaches and mosquito larvae [34-36]. Soap has also been used as insecticide against different pest insects [25]. Because soap and hydrogen peroxide are oxidants or because they are capable of releasing toxic by-products, such as free radicals (hydroxyl, superoxide,

Table 3 Strength of association between selection of mosquitoes at the larval stage with different sublethal concentrations of soap or hydrogen peroxide $\left(\mathrm{H}_{2} \mathrm{O}_{2}\right)$ and mosquito tolerance to permethrin $0.75 \%$ at the adult stage

\begin{tabular}{lllllll}
\hline & \multicolumn{5}{c}{ Comparison of mortality rates between groups } \\
\cline { 2 - 7 } & LC10 vs control & LC20 vs control & LC30 vs control & LC20 vs LC10 & LC30 vs LC10 & LC30 vs LC20 \\
\hline Soap & $1.98^{* *}$ & $6.09^{* *}$ & $8.09^{* *}$ & $3.07^{* *}$ & $4.08^{* *}$ & 1.33 (NS) \\
$\mathrm{H}_{2} \mathrm{O}_{2}$ & $4.81^{* *}$ & $6.58^{* *}$ & $7.45^{* *}$ & 1.37 (NS) & 1.54 (NS) & 1.13 (NS) \\
\hline
\end{tabular}

$\mathrm{LC10}, \mathrm{LC20}, \mathrm{LC} 30$ refer to sublethal concentrations of either soap or $\mathrm{H} 2 \mathrm{O} 2$ used to select mosquitoes at the larval stage (LC10, LC20, LC30 concentrations leading to 10,20 or $30 \%$ mortality rate); control, untreated group; NS, Non significant ${ }^{*}, \mathrm{P}<0.05 ; * *, \mathrm{P}<0.001$. 
or lipid peroxyl radicals), they could act by inducing oxidative stress which effect could be dramatic for mosquito larvae. It is likely that the low susceptibility detected in field larvae could be associated to increase tolerance to oxidative stress. It was demonstrated for An. gambiae that, oxidative stress genes such as oxidase resistance (OXR1) apart from protecting against oxidative stress, also regulates the basal level of catalase and glutathione peroxidase expression, two enzymes involved in the detoxification of hydrogen peroxide and several other xenobiotics [37]. Although neither $k d r$ nor metabolic resistance assays were conducted, it is likely that these two mechanisms are responsible for the limited susceptibility of An. gambiae to permethrin. Assessments conducted between 2009 and 2012 in both Douala and Yaoundé, identified $k d r$ as the main resistance mechanism in both cities (frequency > 60\%) and metabolic resistance also implicated in Yaoundé $[9,10,38]$. It is probable that detoxification genes, such as CYP6P3 and CYP6M2 highly prevalent in DDT and pyrethroids resistant mosquito specimens emerging from polluted sites [9], could be involved in resistance to these xenobiotics. In the light of previous studies cuticular mechanisms (bioaccumulation of pollutants or reduced cuticular penetration) might have a limited role in xenobiotic or pyrethroid detoxification in mosquitoes originating from polluted or cultivated sites in Yaoundé [9].

Studies conducted so far in the city of Yaoundé, suggested different tolerance levels driving niche partitioning between populations of An. coluzzii and An. gambiae [13]. Higher ammonia tolerance display by An. coluzzii predominant in urban centres was considered as an adaptive trait to urban areas given that this toxicant occurred on average at higher concentration in urban larval habitats compared to rural ones, where An. gambiae predominates [13]. Yet no implication of this distribution on mosquito tolerance to insecticide has so far been established and both An. coluzzii and An. gambiae have been recorded resistant to pyrethroid $[9,10]$. Despite the fact that the sample used for the study consisted almost exclusively of An. coluzzii specimens, phenotypes with different levels of tolerance to soap and $\mathrm{H}_{2} \mathrm{O}_{2}$ were recorded and this probably highlights a process of microevolution leading at improving this species capacity of adaptation to new environmental conditions. Consistent with these observations, cytological analysis conducted on An. coluzzii and An. gambiae across Cameroon recorded different chromosomal arrangements induced by directional or balancing selection strongly correlated to prevailing ecogeographical conditions [39].

It also appeared from the study that selection with soap or $\mathrm{H}_{2} \mathrm{O}_{2}$ reduced significantly the proportion of larvae emerging as adults. The following suggest that tolerance to pollutants occurs at significant fitness cost as reported elsewhere [40]. It is possible that in the nature, because xenobiotics could be sequestrated or diluted in large water bodies, their impact on mosquito fitness might be attenuated. Further investigations might be necessary to capture the influence of the current adaptation of mosquito populations to polluted habitats on subsequent generation's fitness.

\section{Conclusion}

Because pyrethroid resistance limit the efficiency of control interventions, identifying compounds responsible for pyrethroid resistance emergence is becoming critical for improving control strategies. The present study, showed that alongside insecticide use, selection by noninsecticidal compounds such as soap and hydrogen peroxide, affect adult mosquito tolerance to pyrethroids. With the current adaptation of mosquitoes to urban areas, it is important that such findings be taken in consideration by current and future control programmes.

\section{Competing interests}

The authors declare that they have no competing interests.

\section{Authors' contributions}

Conceived and designed the study protocol: CAN, Participated in field and laboratory analyses, MYG, BTF, EK, PAA, CAN. Critically revised the manuscript: CC, NF, PAA. Interpreted, analysed data and wrote the paper: CAN. All authors read and approved the final version of the manuscript.

\section{Acknowledgements}

This work was supported by a Wellcome Trust Intermediate Fellowship in Public Health and Tropical Medicine (WTO86423MA) to CAN.

\section{Author details}

Laboratoire de Recherche sur le Paludisme, Organisation de Coordination pour la lutte Contre les Endémies en Afrique Centrale (OCEAC), P.O. Box 288, Yaoundé, Cameroon. ${ }^{2}$ Faculty of Sciences, University of Yaoundé I, P.O. Box 337, Yaoundé, Cameroon. ${ }^{3}$ Institut de Recherche pour le Développement (IRD), UR 016, 911, avenue Agropolis, P.O. Box 64501, 34394 Montpellier cedex 5, France. ${ }^{4}$ Vector group, Liverpool School of Tropical Medicine, Pembroke Place, Liverpool L3 5QA, UK.

Received: 4 March 2014 Accepted: 27 July 2014

Published: 3 August 2014

\section{References}

1. WHO: World Malaria Report 2012. Geneva, Switzerland: World Health Organization, Global Malaria Programme; 2012:259.

2. Ranson H, N'Guessan R, Lines J, Moiroux N, Nkuni Z, Corbel V: Pyrethroid resistance in African anopheline mosquitoes: what are the implications for malaria control? Trends Parasitol 2011, 27:91-98.

3. WHO Malaria Policy Advisory Committee and Secretariat: Malaria policy advisory committee to the WHO: conclusions and recommendations of september 2012 meeting. Malar J 2012, 11:424.

4. Nwane P, Etang J, Chouaibou M, Toto J, Kerah-Hinzoumbe C, Mimpfoundi $\mathrm{R}$, Awono-Ambene $\mathrm{H}$, Simard F: Trends in DDT and pyrethroid resistance in Anopheles gambiae s.s. populations from urban and agro-industrial settings in southern Cameroon. BMC Infect Dis 2009, 9:163.

5. Ndjemai H, Patchoke S, Atangana J, Etang J, Simard F, Bilong Bilong C, Reimer L, Cornel A, Lanzaro C, Fondjo E: The distribution of insecticide resistance in Anopheles gambiae s.l. populations from Cameroon: an update. Trans R Soc Trop Med Hyg 2008, 103:1127-1138.

6. Yadouleton A, Asidi A, Djouaka R, Braima J, Agossou C, Akogbeto M: Development of vegetable farming: a cause of the emergence of insecticide resistance in populations of Anopheles gambiae in urban areas of Benin. Malar J 2009, 8:103. 
7. Chouaibou M, Etang J, Brevault T, Nwane P, Hinzoumbe C, Mimpfoundi R, Simard F: Dynamics of insecticide resistance in the malaria vector Anopheles gambiae s.l. from an area of extensive cotton cultivation in northern Cameroon. Trop Med Int Health 2008, 13:476-486.

8. Muller P, Choua IM, Pignatelli P, Etang J, Walker ED, Donnelly MJ: Pyrethroid tolerance is associated with elevated expression of antioxidants and agricultural practice in Anopheles arabiensis sampled from an area of cotton fields in Northern Cameroon. Mol Ecol 2008, 17:1145-1155.

9. Fossog Tene B, Poupardin R, Costantini C, Awono-Ambene P, Wondji CS, Ranson $\mathrm{H}$, Antonio-Nkondjio C: Resistance to DDT in an urban setting: common mechanisms implicated in both $\mathrm{M}$ and S Forms of Anopheles gambiae in the city of Yaoundé Cameroon. PLoS One 2013, 8:e61408.

10. Antonio-Nkondjio C, Fossog B, Ndo C, Djantio B, Togouet S, AwonoAmbene P, Costantini C, Wondji C, Ranson H: Anopheles gambiae distribution and insecticide resistance in the cities of Douala and Yaounde (Cameroon): influence of urban agriculture and pollution. Malar J 2011, 10:154

11. Tene Fossog B, Kopya E, Ndo C, Menze-Djantio B, Costantini C, Njiokou F, Awono-Ambene P, Antonio-Nkondjio C: Water quality and Anopheles gambiae larval tolerance to pyrethroids in the cities of Douala and Yaounde (Cameroon). J Trop Med 2012, 2012:1-10.

12. Kamdem C, Fossog B, Simard F, Etouna J, Ndo C, Kengne P, Bousses $P$, Etoa F, Awono-Ambene P, Fontenille D, Antonio-Nkondjio C, Besanski NJ: Anthropogenic habitat disturbance and ecological divergence between incipient species of the malaria mosquito Anopheles gambiae. PLoS One 2012, 7:e39453.

13. Tene Fossog B, Antonio-Nkondjio C, Kengne P, Njiokou F, Besansky N, Costantini C: Physiological correlates of ecological divergence along an urbanization gradient: differential tolerance to ammonia among molecular forms of the malaria mosquito Anopheles gambiae. BMC ECOl 2013, 13:1

14. Hoffmann A, Parsons P: Extreme environmental change and evolution Cambridge: Cambridge University Press; 1997.

15. Patil N, Lole K, Deobagkar D: Adaptative thermo tolerance and induced cross tolerance to proporxur insecticide in mosquitoes. Med Vet Entomol 1996, 10:277-282.

16. Raghavendra K, Barik T: Development of larval thermotolerance and its impact on adult susceptibility to malathion insecticide and Plasmodium vivax infection in Anopheles stephensi. Parasitol Res 2010, 107:1291-1297.

17. Nkya T, Akhouayri I, Kisinza W, David J: Impact of environment on mosquito response to pyrethroid insecticides: facts, evidences and prospects. Insect Biochem Mol Biol 2013, 43:407-416.

18. Li X, Schuler M, Berenbaum M: Molecular mechanisms of metabolic resistance to synthetic and natural xenobiotics. Annu Rev Entomol 2007, 52:231-253.

19. Poupardin R, Reynaud S, Strode C, Ranson H, Vontas J, David J: Cross-induction of detoxification genes by environmental xenobiotics and insecticides in the mosquito Aedes aegypti: Impact on larval tolerance to chemical insecticides. Insect Biochem Mol Biol 2008, 38:540-551.

20. David J, Boyer S, Mesneau A, Ball A, Ranson H, Dauphin-Villemant C: Involvement of cytochrome P450 monooxygenases in the response of mosquito larvae to dietary plant xenobiotics. Insect Biochem Mol Biol 2006, 36:410-420.

21. Mireji P, Keating J, Kenya E, Mbogo C, Hudson N, Osir E, Githure J, Beier J: Differential induction of proteins in Anopheles gambiae sensu stricto (Diptera: culicidae) larvae in response to heavy metal selection. Int J Trop Insect Sci 2006, 26:214-226

22. Baldwin $\mathrm{R}$, Koehler $\mathrm{P}$ : Toxicity of commercial available household cleaners on cockroaches, Blattella germanica and Periplaneta americana. Florida Entomol 2007, 90:703-709.

23. Xue RD, Qualls W: Larvicidal activity of synthetic disinfectants and antibacterial soaps against mosquito, Culex quinquefasciatus (Diptera: Culicidae). J Med Entomol 2013, 50:137-139.

24. Watt B, Proudfoot A, Vale J: Hydrogen peroxide poisoning. Toxicol Rev 2004, 23:51-57.

25. Szumlas D: Behavioural responses and mortality in German cockroaches (Blattodea: Blattellidae) after exposure to dishwashing liquid. J Econ Entomol 2002, 95:390-398.

26. Gillies M, Coetzee M: A supplement to the Anophelinae of Africa south of the Sahara (Afrotropical region). Publication South Afr Inst Med Res 1987 55:143.
27. Fanello C, Santolamazza F, Della A: Simultaneous identification of species and molecular forms of the Anopheles gambiae complex by PCR-RFLP. Med Vet Entomol 2002, 16:461-464.

28. Cornel A, Collins F: PCR of the ribosomal DNA intergenic spacer regions as a methods for identifying mosquitoes in the Anopheles gambiae complex. Methods Mol Biol 1996, 56:321-332.

29. WHO: Guidelines for laboratory and field testing of mosquito larvicides. Geneva: World Health Organization Communicable Disease Control, Prevention and Eradication WHO Pesticide Evaluation Scheme; 2005:36. WHO/CDS/WHOPES/GCDPP/200513.

30. Abbott W: A method of computing the effectiveness of an insecticide 1925. J Am Mosq Control Assoc 1987, 3:302-303.

31. WHO: Test procedures for insecticide resistance monitoring in malaria vectors. Bio-efficacy and persistence of insecticides on treated surfaces. Geneva: WHO/ MAL/98, 12 Report of the WHO Informal Consultation; 1998:43.

32. Reimer L, Fondjo E, Patchoke S, Diallo B, Lee $Y$, Arash N, Ndjemai H, Atangana J, Traore S, Lanzaro G, Cornel A: Relationship between kdr mutation and resistance to pyrethroid and DDT insecticides in natural populations of Anopheles gambiae. J Med Entomol 2008, 45:260-266.

33. Musasia F, Isaac A, Masiga D, Omedo I, Mwakubambanya R, Ochieng R, Mireji P: Sex-specific induction of CYP6 cytochrome P450 genes in cadmium and lead tolerant Anopheles gambiae. Malar J 2013, 12:97.

34. Abbasi S, Nipaney P, Soni R: Soap solution as an environmentally safe pesticide: for household insects a preliminary investigation. Comp Physiol Ecol 1984, 9:46-48

35. Subra R, Service M, Mosha F: The effect of domestic detergents on the population dynamics of the immature stages of two competitor mosquitoes, Culex cinereus Theobald and Culex quinquefasciatus Say (Diptera: Culicidae). Acta Trop 1984, 41:69-75.

36. Sherman C, Fernandez E, Chan A, Lozano R, Leontsini E, Winch P: La Untadita: a procedure for maintening washbasins and drums free of Aedes aegypti based on modification of existing practices. Am J Top Med Hyg 1998, 58:257-262.

37. Jaramillo-Gutierrez G, Molina-Cruz A, Kumar S, Barillas-Mury C: The Anopheles gambiae Oxidation Resistance 1 (OXR1) gene regulates expression of enzymes that detoxify reactive oxygen species. PLoS One 2010, 5:e11168.

38. Antonio-Nkondjio C, Defo-Talom B, Tagne-Fotso R, Tene-Fossog B, Ndo C, Lehman L, Tchuinkam T, Kengne P, Awono-Ambene P: High mosquito burden and malaria transmission in a district of the city of Douala, Cameroon. BMC Infect Dis 2012, 12:275

39. Simard F, Ayala D, Kamdem G, Pombi M, Etouna J, Ose K, Fotsing J, Fontenille D, Besansky N, Costantini C: Ecological niche partitioning between Anopheles gambiae molecular forms in Cameroon: the ecological side of speciation. BMC Ecol 2009, 9:17.

40. Mireji P, Keating J, Hassanali A, Mbogo C, Muturi M, Githure J, Beier J: Biological cost of tolerance to heavy metals in the mosquito Anopheles gambiae. Med Vet Entomol 2010, 24:101-107.

\section{doi:10.1186/1475-2875-13-296}

Cite this article as: Antonio-Nkondjio et al.: Exposure to disinfectants (soap or hydrogen peroxide) increases tolerance to permethrin in Anopheles gambiae populations from the city of Yaoundé, Cameroon. Malaria Journal 2014 13:296.

\section{Submit your next manuscript to BioMed Central and take full advantage of:}

- Convenient online submission

- Thorough peer review

- No space constraints or color figure charges

- Immediate publication on acceptance

- Inclusion in PubMed, CAS, Scopus and Google Scholar

- Research which is freely available for redistribution 